\title{
What's Sex Got to Do with It? Challenges for Incorporating Sexuality into Family Planning Programs
}

\author{
Kirsten Moore \\ Judith F. Helzner
}

Follow this and additional works at: https://knowledgecommons.popcouncil.org/departments_sbsr-rh

Part of the Demography, Population, and Ecology Commons, Family, Life Course, and Society Commons, and the International Public Health Commons How does access to this work benefit you? Let us know!

\section{Recommended Citation}

Moore, Kirsten and Judith F. Helzner. 1996. "What's sex got to do with It? Challenges for incorporating sexuality into family planning programs." New York: Population Council and IPPF/WHR. 
KIRSTEN MOORE is co-editor with Sondra Zeidenstein of Learning About Sexuality: A Practical Beginning and co-author with Lor Heise and Nahid Toubia of Sexual Coercion and Reproductive Health: A Focus on Research. Formerly Manager of the Gender, Family, and Development Program at the Population Council, she is urrently pursuing her master's degree in public affairs.

JUDITH F. HELZNER is Director of Program Coordination at the International Planned Parenthood Federation/Western Hemisphere Region. She has worked extensively on gender issues, quality of eare, and sexual health.

\section{(1) Population Council}

ffili International Planned Parenthood Federation, עIIJ), Western Hemisphere Region, Inc.

\section{What's Sex Got To With It?}

Challenges for

Incorporating

Sexuality into

Family Planning

Programs

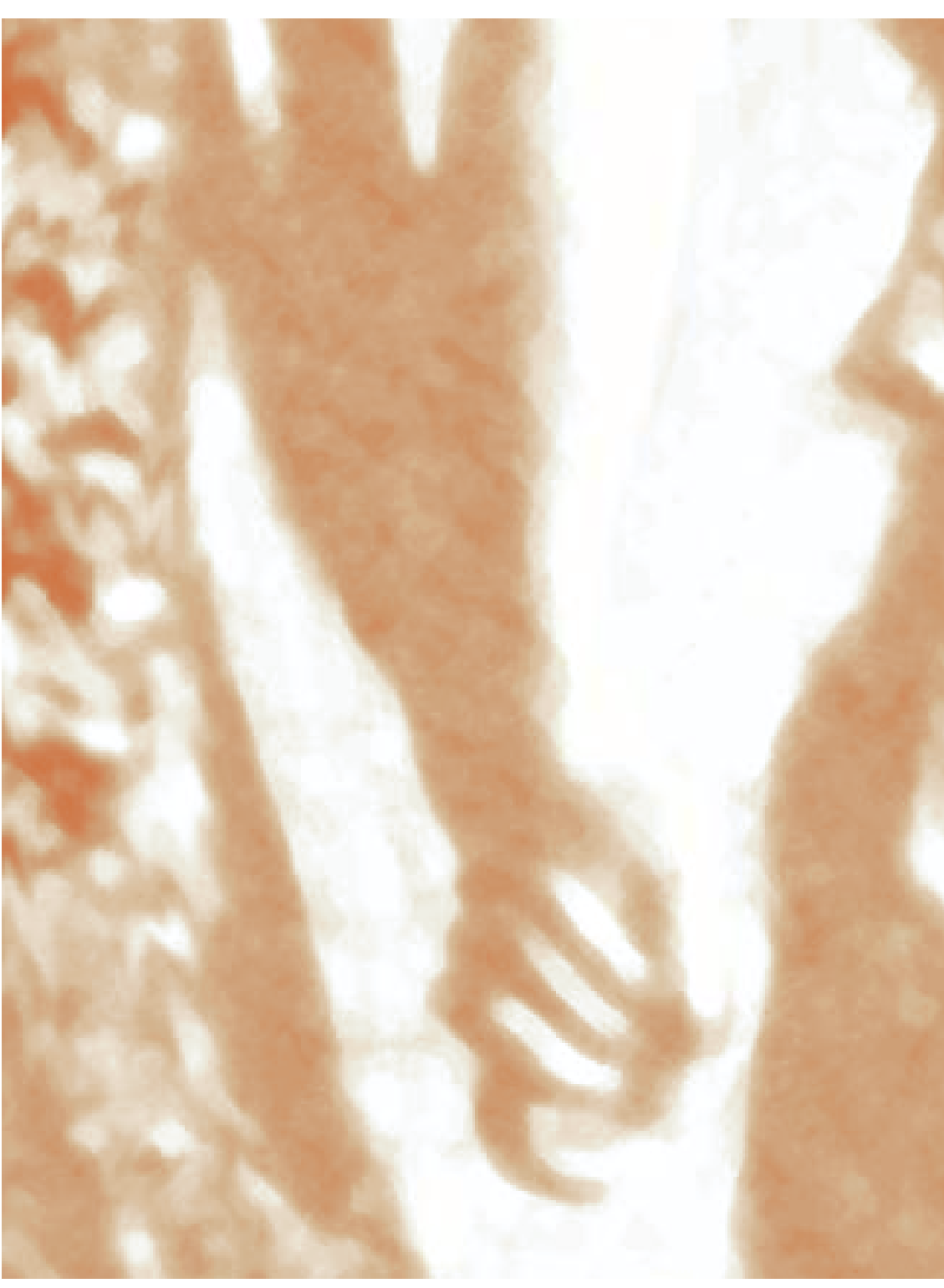




\section{What's Sex Got To Do With It?}

Challenges for Incorporating Sexuality into Family Planning Programs

Kirsten Moore and Judith F. Helzner 


\section{Moore, Kirsten.}

What's sex got to do with it? : challenges for

planning programs /

$$
\text { incorporating sexuality into family }
$$

Kirsten Moore and Judith F. Helzner.

$$
\text { p. } \mathrm{cm} \text {. }
$$

ISBN 0-87834-088-2 (pbk. : alk. paper)

1. Birth control clinics. 2. Hygiene, Sexual. 3. Sex instruction. I. Helzner, Judith F. II. Title.

\section{HQ766.M564 1997}

363.9'6--dc2 1

The Population Council seeks to improve the wellbeing and reproductive health of current and future generations around the world and to help achieve a humane, equitable, and sustainable balance between people and resources. The Council, a nonprofit, nongovernmental research organization established in 1952, has a multinational board of trustees; its New York headquarters supports a global network of regional and country offices.

Population Council

One Dag Hammarskjold Plaza

New York, NY 10017 USA

tel: (212) 339-0500

fax: (212) 755-6052

email: pubinfo@popcouncil.org

http://www.popcouncil.org

The International Planned Parenthood Federation/Western Hemisphere Region, Inc. (IPPF/WHR) and its 46 member family planning associations promote the recognition and exercise of family planning as a basic human right, within the context of IPPF's worldwide Strategic Plan "Vision 2000." This Plan directs family planning organizations around the globe to work on meeting six challenges: To satisfy unmet need, improve sexual and reproductive health, eliminate unsafe abortion, work towards the empowerment of women, address the needs of youth, and promote quality of care.

IPPF/WHR, Inc.

120 Wall Street

New York, NY 10005-3902 USA

tel: (212) 248-6400

fax: (212) 248-4221

email: info@ippfwhr.org

http://www.ippfwhr.org 


\section{$C_{\text {ontents }}$}

$\begin{array}{lr}\text { Preface } & 4\end{array}$

$\begin{array}{ll}\text { Introduction } & 6\end{array}$

Myth ${ }^{* 1}$ : Sexuality is a personal matter that people are unwilling to discuss.

Myth ${ }^{* 2}$ : Sex is a voluntary activity between individuals of equal status.

Myth \#3: Clients prefer family planning methods that do not interfere with coitus.

Myth \#4: Family planning providers are prepared to respond to clients' questions and needs concerning sexuality.

Myth \#5: Addressing sexuality will overburden family planning programs.

Poems from the Belize Family Life Association Community Workshop 


\section{Pertace}

W

hat does sex have to do with it? The answer may seem obvious to people who work in family planning programs or conduct research on those programs. But in practice this connection is rarely acknowledged. For decades, family planning programs have been designed on the assumption that providing information and technologies to clients, who are defined almost exclusively as women, will suffice to reduce unwanted and unplanned pregnancy. In recent years, policymakers, program managers, and researchers have begun to agree on the importance of improving the quality of family planning services. Today, however, there is a growing recognition that paying greater attention to clients' needs is still not enough. As long as family planning programs ignore the context in which individuals and couples make decisions about fertility and contraception, they will be limited in their impact and effectiveness. In addition, the continued spread of the HIV pandemic and increased visibility of such issues as women's rights and sexual coercion are forcing many people to rethink the appropriateness of a narrow focus on reducing unwanted births.

Increasingly, those working on research and service delivery innovations around the world are exploring the complicated and dynamic connection between sexuality and family planning. The Population Council and the International Women's Health Coalition, for example, have compiled research and program experiences that provide insights about men's and women's perceptions and experiences of their sexuality and intimate relationships. Together they published a book, Learning About Sexuality: A Practical Beginning, that looks at how sexuality and power differences between men and women shape contraceptive practice and reproductive health. It also documents how communitybased activists and family planning and reproductive health counselors can help individuals move toward satisfactory sexual lives and greater wellbeing. Moreover, in 1992, the International Planned Parenthood Federation (IPPF) challenged its family planning affiliates around the world to experiment with services to improve sexual and reproductive health. Since then, IPPF's Western Hemisphere Region (IPPF/WHR) has been learning more about how providers' attitudes toward sexuality and gender roles affect the services clients receive. Consequently, IPPF/WHR has developed innovative approaches to changing those attitudes to better meet the sexual health needs of their clients.

We thought it would be valuable to researchers and practitioners alike to bring these two perspectives together. In February 1996, IPPF/WHR and the Population Council's Ebert Program on Critical Issues in Reproductive Health 
jointly hosted a meeting on the challenge of incorporating sexuality into family planning. We compiled this report after concluding that the ideas and strategies presented during the meeting merited wider recognition and debate within the family planning field. We hope it encourages others in the field to think about how to offer family planning and reproductive health services in ways that promote individuals' ability to identify and meet their sexual health needs and in ways that enhance equality between intimate partners. This report draws principally on the discussions from that day as well as on our perspectives as organizers.

Many thanks to the presenters-Julie Becker, Ann Blanc, Debra Boyer, Margarita Diaz, Hilary Hughes, Robert Miller, Elaine Murphy, Jewel Quallo-Rosberg, Debbie Rogow, and Lindsay Stewart-whose experiences and reflections provided the foundations of this report. Judith Bruce and Elizabeth McGrory were instrumental in helping us to clarify our objectives and messages in both the meeting and this report while Elizabeth Coleman, Victoria Jennings, and Geeta Rao Gupta provided feedback that helped us shape this report for a wider audience. Diane Rubino handled the many administrative facets of this project flawlessly. Finally, we wish to thank our respective donors. Within IPPF/WHR, funds for the meeting and report were provided by the Ford Foundation. The Councils Ebert Program on Critical Issues in Reproductive Health was a co-sponsor of this meeting with funding from the John D. and Catherine T. MacArthur Foundation. Additional funding for this report was provided by the Ford Foundation through the Council's Gender, Family, and Development program.

Kirsten Moore, Population Council Judith F. HELZNER, IPPF/WHR 


\section{Inroduction}

I

$\mathrm{n}$ recent years, many family planning program managers have begun to consider whether and how to of fer a broader range of reproductive health services, most notably prevention and treatment of sexually transmitted diseases. This interest, which in many countries began as a result of trying to cope with the AIDS pandemic, grew as a result of the 1994 International Conference on Population and Development. The conference's Programme of Action calls for family planning services to be situated within a reproductive health framework that emphasizes individual health and welfare, the empowerment of women, and gender equity. If family planning programs are to achieve this goal, they need to pay closer attention to such issues as sexuality and the distribution of power within intimate and family relationships.

The narrow scope of family planning programs seldom addresses differing norms of male and female sexual and reproductive behavior. Moreover, many program staff reason that sexual and reproductive behavior is a reflection of culture and that family planning services cannot or should not interfere with culture. While others believe that gender and power dynamics are critical to safe and effective contraceptive use, they are struggling to address these issues within systems that are designed, funded, and evaluated according to narrow indicators such as contraceptive "acceptors" and births averted. Learning more about the dynamics of power within intimate relationships, and trying to alter them, presents fundamental challenges for family planning programs and research.

To engage international program managers and researchers in this learning process, the International Planned Parenthood Federation/Western Hemisphere Region (IPPF/WHR) and the Population Council's Robert H. Ebert Program on Critical Issues in Reproductive Health hosted a workshop on 6 February 1996 called "What's Sex Got to Do with It? Challenges for Incorporating Sexuality into Family Planning Programs." (A list of participants appears on pages 26-28.) The day's discussion highlighted the need for family planning programs to pay greater attention to the implications of clients' social context, particularly partnership relations and sexual behavior, in order to ensure appropriate method choice and successful contraceptive use. Further, the pioneering initiatives discussed indicate that family planning programs can and do have a role to play in helping individuals and couples develop greater self-awareness, communication, and decisionmaking skills with regard to their own sexual and reproductive behavior. The meeting examined five myths that have prevented family planning and reproductive health services from dealing directly with issues of sexuality and gender. 
1. Sexuality is a personal matter that people are unwilling to discuss.

2. Sex is a voluntary activity between individuals of equal status.

3. Clients prefer family planning methods that do not interfere with coitus.

4. Family planning providers are prepared to respond to clients' questions and needs concerning sexuality.

5. Addressing sexuality will overburden family planning programs.

In addition to exploring the roots of these myths, researchers and program staff shared successful strategies for overcoming the practical challenges they have faced in trying to bring greater recognition of sexuality and gender into their work.

Participants included representatives from U.S.-based organizations that deliver family planning information and services internationally, conduct training and research within such programs, or fund work in this area. In addition, there were several participants from family planning programs based in Latin America. (Simultaneous translation was provided for both Spanish and English speakers.) Presentations were made by professionals who have worked in developing countries as well as in the United States.

It should be noted that when we refer in this report to "family planning and reproductive health services," we are talking about a range of issuesincluding sexuality, gender roles, and sexual decisionmaking-that are critical in providing information and counseling about STD and HIV prevention as well as postpartum, abortion, and post-abortion care.

As Kirsten Moore of the Population Council suggested in her opening remarks, "sexuality" is a complex and often confusing term that can be used to describe both individual behavior and cultural norms. In this report, it refers to a social construction of a biological drive. It is dynamic and multidimensional. People derive their sexual identity from their partnerships, behavior and acts, physiological drive, and the meanings they give to these things. Research and program experience show that women often exercise little power with regard to choosing sexual partners, engaging in sexual activity, and protecting themselves from unwanted pregnancy and disease. Consequently, family planning programs are experimenting with new ways to "bring men in." The goal is not simply to increase the total number of contraceptive users, Moore said. Program strategies must recognize that coerced sexual encounters and power inequalities between partners often lead to unwanted pregnancy, disease, and other undesirable outcomes. Helping individuals to develop a better understanding of their sexuality and the motivations of their sexual behavior is a necessary step in helping clients achieve their reproductive intentions. Furthermore, it can be a profoundly empowering experience for the client or couple.

In making the connection between sexuality and family planning, Moore cautioned, it is vital for public health professionals to speak in positive terms. Too often, our professional roles lead us to talk only about the "risk" of unwanted pregnancy, the "threat" of becoming infected with the virus that causes AIDS, or the "menace" of sexual abuse and coercion. As individuals, however, most of us think about our sexuality in a more positive light. We consider the possibilities of pleasure, of forming intimate relationships, of having a child. Our task as individuals and professionals is to help clients find a balance be- 
tween pleasure and risk. This means actively exploring with clients or potential clients the dissonance between cultural notions of what constitutes appropriate sexual behavior for men and women and individuals' actual behavior.

Experience shows that it is possible for family planning programs to effectively address issues of sexuality and relationships, Judith Helzner of IPPF/WHR said at the close of the meeting. Moreover, offering such services has the potential to attract clients as well as improve staff's satisfaction with their work. Indeed, Helzner observed, many of the day's presentations emphasized that sexuality and sexual behavior are integral to the operation of family planning programs, not simply an add on. Program managers should view clients' understanding of their sexuality and the context of their sexual relationships as critical starting points when designing information, education, and communication campaigns or developing counseling approaches. Such attention to sexuality requires a new assessment of the range of fertility regulation strategies as well as new language to facilitate communication on such intimate issues with clients.

Reflecting on IPPF's experiences, Helzner said that innovative programs typically begin with a willingness to listen carefully to people's needs and experiences and a willingness to experiment. Some programs focus on giving people more information about their bodies or asking them if they would like to include their partners in future counseling sessions. Others focus on helping clients develop communication and decisionmaking skills, which can help them negotiate change in sexual behavior and contraceptive use with their partners. Analyzing and quantifying some of these changes will be necessary to help justify further investment in this area and to sustain this momentum.

In almost any setting, the politics surrounding issues of sexuality are typically complicated and sometimes contradictory, and they call for careful planning on the part of those who seek to undertake such work. This report presents some practical lessons for researchers studying sexuality and for managers who wish to incorporate sexuality in their family planning programs. 
Precisely because sex is so private, people long for constructive opportunities to talk about sexual experiences, concerns, and needs.

To find ways to make individuals more comfortable discussing their sexual lives with family planning providers and researchers.

$\mathbf{T}$

here is a paucity of good information worldwide about individuals' sexual behavior. Many attribute this to the fact that conducting research on this topic is difficult, if not impossible. At first demographers and social scientists were skeptical as to the feasibility and appropriateness of asking women about their contraceptive use. But as the population field developed, questions related to health, reproductive intentions, contraceptive use, and sexual behavior were routinely incorporated into the World Fertility Surveys and their successor, the Demographic and Health Surveys. By the end of 1995, these surveys had been conducted in 60 countries, often two or three times, said Ann Blanc of DHS. Few women and men refuse to answer personal questions about coital frequency, Blanc said. Some service providers also question clients about aspects of their behavior. According to the observational Situation Analysis studies, 36 percent of service providers in Kenya asked clients about the nature of their sexual relations. In Zanzibar, the figure was 59 percent.

Accurate data are critical in designing services that are responsive to women's needs. Blanc posed the example of married women who report low coital frequency because their husbands have migrated to an urban area or another country for work. Such women may desire a family planning method they need to use only when they have sex. If many women in a community report similar contraceptive preferences, clinics might reorient their services by training counselors and providers and ensuring a steady supply of barrier methods.

Some questions that might yield valuable information include: Who are their partners? Do their partners have partners? How often do they have sex? What kind of sex do they have? What are their perceptions of pleasure? What are their perceptions of risk? Who decides when to have sex? If the partner doesn't want to, what strategies does she or he use to refuse sex? Do notions of parenthood and/or partnership influence sexual behavior? Program managers and researchers seeking answers to these questions are still learning the most appropriate and optimal ways in which to generate reliable information. Geeta Rao Gupta noted that researchers who conducted a study supported by the Women 
and AIDS Research Program found that young women in Thailand were more comfortable speaking one-on-one than answering a written survey. She suggested that the act of writing down their answers made their behavior seem more real than they were prepared to acknowledge-even to themselves.

Hilary Hughes of IPPF spoke of the need to find new ways to collect sensitive information. IPPF's Sexual Health Project (SHP), whose services address both family planning and STD/HIV prevention and care, has made some inroads in getting people to talk about the issues affecting their lives in Gambia, Ghana, Tanzania, Burkina Faso, India, and the Dominican Republic. Project staff begin by initiating discussions among different community groups around concrete issues related to sexual and reproductive health, including the quality of male/ female relations; the ability to enjoy sexual relations without fear of unwanted pregnancy, disease, or violence; and concerns about the ability to conceive. The community groups then prioritize key concerns, suggest indicators by which to measure change, and identify agents and methods for data collection. In Tanzania, for example, the groups identified three key concerns: drunkenness, which can lead to the breakdown of relationships within families that are struggling financially; promiscuity, which can lead to discord between couples and lack of trust and respect in sexual relations; and teenage pregnancy. With regard to promiscuity, community members recommended the following indicators: the number of divorces or separations over a defined period of time; the number of relationship problems for which outside help is sought; and the number of husbands who beat their wives or engage in other forms of domestic violence. Suggested sources for data collection included community-based distribution agents, traditional counselors, community elders, and a sample of the sexually active adult population identified through a community questionnaire.

These discussions give SHP staff an opportunity to answer questions, correct misconceptions or misinformation, and explore myths related to sexual and reproductive health. Women and men often use slang or euphemisms that may not be immediately apparent to a researcher or clinician. By recognizing these terms, SHP and clinic staff can use appropriate language in research instruments and one-on-one counseling.

The SHP found that although sexuality is a personal matter, it is also a community issue. The problems that individuals experienced were not simply the result of individual behavior, but were influenced by community conditions and norms, such as gender roles, economic opportunities, or power of elders. SHP staff have found that discussions of sexuality and female/male interactions, both within the community and in the clinic, can be a powerful starting point for social change. For example, discussions of marital discord in one Ghanaian village elicited vastly different statements from men and women. As the discussions progressed, women and men began to appreciate the root causes, to listen to one another, and eventually to craft solutions.

Well-facilitated group or community discussion on sensitive issues not only provides valuable data but also constitutes a service to clients and to potential clients. The SHP has found that the group setting allows people to develop better communication with those with whom they are in conflict and to form alternative visions for the future. As evidenced in the following section, even victims of abuse or coercion report that simply being asked about their experiences can be a cathartic and beneficial experience. 


\title{
Sex is a voluntary activity between individuals of equal status.
}

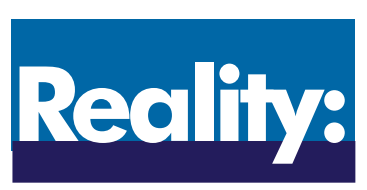

\section{Power dynamics within a relationship strongly influence sexual activity; a significant number of women and girls, and sometimes boys, report they are coerced into sex.}

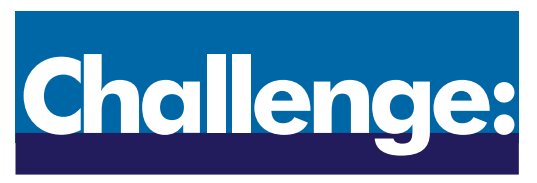

\author{
To identify and alleviate power \\ inequalities among intimate \\ partners.
}

$\mathrm{n}$ recent years, quantitative and qualitative data have challenged the assumption that family planning clients (typically women) are partners in consensual, monogamous sexual relationships. The data reveal that a significant proportion of women, girls, and sometimes boys are forced, coerced, or tricked into having sex. Debra Boyer of the Center for Health Training and Lindsay Stewart of IPPF/WHR presented data on abuse collected in family planning clinics in the United States and Latin America. They reviewed what is known or hypothesized in the literature about the connections between experiences of abuse and coercion and contraceptive use, and they provided some examples of what clinics can do to better respond to their clients' needs.

Boyer reported findings from a recent study conducted in fourteen family planning clinics in five states in the United States. Researchers asked 2,226 women about their experiences of physical, sexual, and emotional abuse over their lifetimes. One-third of the women reported sexual abuse and one-third reported violence. Stewart presented similar data from other parts of the world. In each case, surprising numbers of women reported a history of physical, sexual, or emotional abuse, often at an early age, and a large majority of them knew their abusers.

In addition, both Boyer and Stewart presented data that indicate a strong correlation between sexual abuse or coercion and adolescent pregnancy. Studies from both developed and developing countries reveal that girls and women who have been sexually abused exhibit a sense of dissociation, or lack of physical connection with their body. They also have lower self-esteem and often feel unloved. As a result, they are often unable to maintain clear and appropriate personal boundaries, particularly with regard to their bodies, and are frequently unable to say "no." These findings raise doubts about whether girls who have been sexually abused can accurately be said to "consent" to sexual activity.

Boyer and a colleague conducted an earlier study in family planning clinics in the state of Washington. Their findings revealed that sexual abuse is strongly correlated with earlier age at first sex, more partners, greater age dis- 
parities between partners, more frequent use of alcohol and drugs (which can lead to high-risk sexual behavior), and less frequent use of contraceptives. It is also the strongest predictor of repeat pregnancies. Indeed, ten years of research in this area led Boyer to hypothesize that sexual abuse is perhaps the primary indicator for unwanted adolescent pregnancy in the United States. This pattern may not hold true in developing countries, where women often marry at a younger age. Nevertheless, physical, emotional, and sexual abuse has disturbing implications for future patterns of sexual behavior, as well as harmful consequences for physical and psychosocial health.

In another investigation, IPPF/WHR affiliates in Peru and Colombia collected data on experience of sexual abuse among young people who sought medical and psychological counseling. More than half said they had been sexually abused in the preceding 12 months or exhibited signs of recent sexual abuse. Although the sample was selective, the findings suggest that sexual abuse is closely related to sexual risk-taking and unwanted pregnancy.

Debbie Rogow, independent consultant, suggested that, given this history of abuse, the descriptive category "sexually active" may be a misnomer. Many young women who are having sex might more accurately be described as "sexual acceptors" rather than "sexually active." The word "active," moreover, might better describe girls and women who make choices on their own behalf-either to have sex, or not to.

Margaret Hempel of the Ford Foundation noted that many girls lack positive language with which to describe their sexuality, desires, and experiences. She said it is critical to promote a healthy sexual identity among girls that allows them to develop appropriate boundaries, take pride in their bodies, and make decisions that affect their health. Martha Brady of the Population Council added that participation in a wide range of sports activities, from basketball to dance, may help young girls develop a more positive self-image and a sense of control.

Although boys and men may also experience sexual abuse, and women are sometimes the perpetrators of abuse, sexual coercion and violence is an overwhelmingly male pursuit against women. Explanations for this are still emerging and are contested. However, it is widely believed that cultural definitions of masculinity and femininity have harmful implications for women and men. Indeed, these notions of masculinity and femininity must change if girls and women are to develop a greater sense of agency. Education programs about pregnancy and disease prevention can help men and boys develop a healthier sense of manhood and talk about what it takes to be a good lover, partner, or parent. Men and boys may appreciate an opportunity to learn more about the reproductive physiology and health of the women they care about. And they may become supporters of women's reproductive choices as well as becoming responsible partners themselves.

Collecting data on sexual abuse raises a number of challenges, including some important ethical concerns. Boyer, for example, said she thinks it is inappropriate to ask clients about current or past abuse by using anonymous questionnaires. Instead, clinic staff should establish relationships with their clients and provide referrals to outside counseling and medical or legal services when requested.

Researchers almost invariably report that women who have been abused are grateful to be asked about their experiences. For many, it is the first 
opportunity to confide in someone, ask questions, or confront their feelings. Despite some initial reluctance, several clinic staff later spoke of the satisfaction they felt after developing a more open exchange with their clients. INPPARES staff in Peru also report better communication with clients and with their colleagues as a result of dealing more openly and explicitly with sexual abuse. This experience has led staff in Peru and Colombia, for example, to develop new educational programs aimed at preventing sexual abuse as well as new services to assist victims of abuse.

In designing and providing services, it is crucial not to assume that clients are engaged in mutually consensual sexual relations. As troubling as the topic of sexual coercion and abuse is, clients and providers both benefit from opportunities for women and men, and girls and boys, to disclose and discuss their experiences. But abusive relationships are not the only thing that family planning practitioners should be on the lookout for. In many cases, limited sexual and reproductive choices stem from societal norms about female and male gender relations. 

methods that do not interfere with coitus.

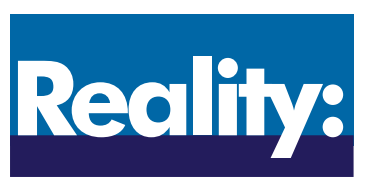

Female clients' tendency to choose methods not associated with coitus is typically more influenced by factors such as provider bias and their male partners' concerns than by consideration of their own needs and options.

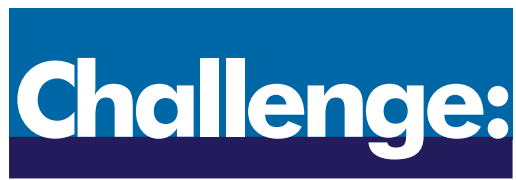

\author{
To help clients make informed \\ decisions about the method best \\ suited to their relationships and \\ needs.
}

\begin{abstract}
$\mathbf{T}$
he positive and negative attributes that providers typically assign to different contraceptive methods, observed Debbie Rogow, "rest on a body of nearly mythical literature-stories that have become so deeply ingrained that the foundations on which they were constructed are no longer questioned." Rogow, an independent consultant, and Margarita Diaz, a nurse practitioner at the University of Campinas in Brazil, carried out a review of provider attitudes toward female barrier methods and male methods. Their analysis showed how the "disadvantages" of these methods can often be traced back to male coital concerns.

Diaz cited some of the most common notions that providers hold with regard to female barrier methods, including the diaphragm, cervical cap, and female condom: women cannot learn how to use these methods properly; their effectiveness is very low; women do not like to manipulate their genitalia; husbands will not accept or support the use of these methods; and these methods decrease the male partner's pleasure. These biases are often either purposefully or unwittingly communicated to clients during counseling sessions. Eventually, the fact that there are higher acceptance rates for methods that do not interfere with coitus is used to support the conclusion that clients prefer nonbarrier methods. This argument is not only circular, Diaz observed, but it often fails to reflect clients' interests. Before designing a course on sexuality for women family planning clients, she and her colleagues conducted interviews with a random sample of 462 women attending their clinic who used various contraceptive methods. As illustrated in Table 1, women did not feel that their sex lives worsened as a result of using a barrier method. In fact, more women reported decreases in sexual satisfaction when using hormonal methods.

In terms of male methods, Rogow observed, researchers and clinical staff have steadfastly refused to investigate the interface between sexual comfort and contraception. Although millions of dollars have been spent to study obstacles to condom use, there has yet to be a questionnaire that asks men if fear of losing an erection when putting on a condom is a central factor in their
\end{abstract}


Changes in Sex Life According to Contraceptive Method Used

\begin{tabular}{lllll} 
Method & Improved & Worsened & $\begin{array}{l}\text { No } \\
\text { Change }\end{array}$ & $\begin{array}{l}\text { No } \\
\text { Information }\end{array}$ \\
\hline $\begin{array}{l}\text { Oral contraceptives } \\
\text { (n=71) }\end{array}$ & $29.6 \%$ & $14.1 \%$ & $49.3 \%$ & $7.0 \%$ \\
$\begin{array}{l}\text { Injectables } \\
(\mathrm{n}=134)\end{array}$ & 20.9 & 11.9 & 61.2 & 6.0 \\
$\begin{array}{l}\text { IUD } \\
(\mathrm{n}=92)\end{array}$ & 30.4 & 13.0 & 53.3 & 3.3 \\
$\begin{array}{l}\text { Barrier methods } \\
(\mathrm{n}=25)\end{array}$ & 24.0 & 4.0 & 68.0 & 4.0 \\
\hline
\end{tabular}

Source: Diaz, M. 1995. In Learning About Sexuality, Sondra Zeidenstein and Kirsten Moore, eds. New York: Population Council and International Women's Health Coalition.

unwillingness to use condoms. This is so despite anecdotal evidence that some men, particularly younger men, prefer to use condoms because it helps them keep an erection longer. In the meantime, the notion that condoms decrease male sensitivity and sexual pleasure during intercourse has been reified in thousands of informational brochures about condoms. In contrast, few brochures mention that condoms may be uncomfortable for a woman if she is not aroused or is dry.

In reviewing the literature on withdrawal, Rogow concluded that myths about its effectiveness and effect on sexual satisfaction have relegated withdrawal beyond the category of secondary methods into an "invisible," but highly popular, non-method. Such myths persist despite the fact that widespread use of withdrawal is cited as one of the principal catalysts behind the fertility transition in Europe. Medical textbooks attribute a variety of psychiatric and urological diseases to withdrawal, although there is no research documenting that the method has a serious detrimental effect on male sexual satisfaction. In fact, what little research there is indicates that withdrawal users often have positive feelings about how the method affects their sexual lives.

An emphasis on male sexual pleasure and a focus on the sexual behavior model of penile-vaginal intercourse dominates thinking and practice within the family planning field. This practice not only subordinates female sexuality and sexual relations to reproduction, but it also elevates male pleasure beyond reproductive responsibility. This does a serious disservice to the goal of helping clients safely and effectively utilize contraceptive methods and achieve their reproductive intentions. First, it undermines communication and joint decisionmaking about reproductive responsibilities and sexual behavior. Second, it limits a woman's ability to utilize a wider variety of methods, and, perhaps, to exercise some control over her sexual life. Finally, it leaves public health professionals with limited options for helping to slow the spread of HIV, STDs, and other forms of reproductive morbidity.

Many in the family planning field are beginning to recognize that the emphasis on modern (usually female) methods, to the exclusion of traditional methods, has seriously undermined male involvement in decisions related to 
reproductive and sexual responsibility. One result of the field's emphasis on women as clients is that men have few sources of information and services offered directly to them. Equally significant, there are also few opportunities for a woman to involve her partner if she so chooses. Many men have internalized the message that because most modern methods are used by women, men do not have to interrupt or lessen their own sexual pleasure. Still other men, even those who have decided to curtail or space births, believe that preventing pregnancy is a woman's responsibility.

Providers' emphasis on hormonal methods or IUDs, to the exclusion of other methods, may further limit a woman's ability to decide when to have sex, with whom, and under what conditions, said Erin McNeill of USAID. In many settings, a wife is, by definition, expected always to be sexually available to her husband. In these instances, methods such as diaphragms, condoms, and periodic abstinence may provide women with some bargaining power with regard to the timing and frequency of sex. In other words, a woman might use a barrier method or other coitus-dependent method to provide an externally enforced break from unwanted sex. Thus, Rogow observed, family planning literature and counseling may actually do a disservice to women by implying that not being sexually available is a "disadvantage" of a method.

Finally, the professional bias that views condoms as a less effective and less desirable method for pregnancy prevention hinders practitioners who are trying to prevent the transmission of HIV/AIDS. Data from the Situation Analysis of Senegal reveal that while condoms are well-stocked in clinics, they are mentioned to only about a quarter of new clients; only 2 percent of new clients hear about them in the context of STDs; and less than 1 percent actually receive them. Equally troubling, there are family planning clinics and programs in which condoms are mentioned only in the context of disease prevention. This could potentially send conflicting messages to clients about their effectiveness in also preventing pregnancy.

New research and approaches are called for to support clients' ability to make and implement informed choices about the most appropriate contraceptive methods for themselves. Informational campaigns, Rogow suggested, could directly address men's concerns about condom usage. Condom distributors could use penis models to show men how to put on condoms correctly and to show women how to put condoms on their partners. Clinics could offer fertility awareness classes for women who lack information about their bodies and reproductive physiology to enhance their decisionmaking ability with regard to sex and contraception. Family planning providers should educate clients about all methods of contraception, natural family planning, and periodic abstinence so that they will fully understand how different methods affect the body and cause the side effects they may have experienced. This process would help clear up misinformation that often goes unaddressed in counseling.

If the goal of services is to help clients achieve their reproductive intentions, it is a mistake for providers to assign absolute positive and negative attributes to specific methods. What is considered a benefit or drawback of a method will differ for clients depending on their own needs and on their relationship with their partners. Helping providers to overcome some of their biases and establish better communication with clients about their histories, relationships, needs, and goals is the subject of the next section. 

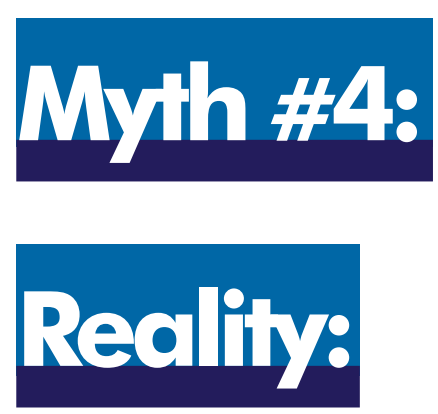

Family planning providers are prepared to repond to clients" questions and needs concerning sexuality.

Providers may know how to explain proper use of a family planning method, but few are trained in how to facilitate communication with clients-particularly about complex and intimate topics.

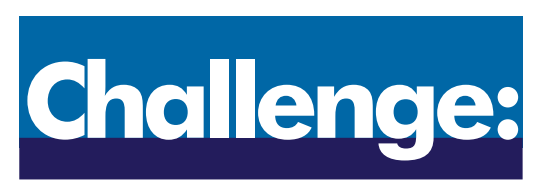

\author{
To help providers develop the \\ necessary values, communication \\ skills, and technical information to \\ respond to clients' sexual con- \\ cerns.
}

\begin{abstract}
“N
o woman walks into a clinic as a blank slate," said Margarita Diaz. "Rather, she comes in with a history of sexual and reproductive behavior as well as motivations and biases about different methods." These attitudes, she said, are based on her own knowledge and experience, her relationship with her partner, his opinion, and perhaps that of her family and peers. Because providers are limited by their training, job description, and time, few make an effort to elicit this history. Yet this information has a significant bearing on what method is most appropriate for the client, whether the client will be able to use it safely and successfully, and whether the client also needs to consider disease prevention. Attention to these underlying factors can also help people have safer and more satisfying sexual relations.
\end{abstract}

IPPF affiliates in Brazil, Honduras, and Jamaica have collaborated with IPPF/WHR's HIV/STD prevention program to help close the gap between clients' needs and providers' beliefs about gender roles and sexual behavior. Rather than simply adding another element to family planning services, said Julie Becker of IPPF/WHR, the project aimed to improve the quality of services by helping clients articulate their needs so that staff could better address them. Although they were working without the benefit of a model for changing the way services were offered, staff showed a keen interest in the subject of sexuality and helping people with their sexual lives. Furthermore, the threat or potential threat of AIDS provided their work with a real sense of urgency as well as a starting point around which staff could organize.

The three programs-in Brazil, Honduras, and Jamaica-began with peer observation of counseling sessions and a review of the staff's technical knowledge, skills, values, and attitudes related to HIV. The findings revealed a somewhat didactic counseling process in which information on methods passed only from provider to client. Staff treated condoms as a back-up contraceptive method, with little reference to STDs and virtually no guidance on how to use the method properly. They generally had an easier time raising the subject of 
sexuality with younger clients than with older ones. And they tended to judge clients' sexual behavior based on their own values and biases. To their credit, staff had a fairly accurate perception of their clients' risk of being infected with HIV or another STD. However, they rarely considered the broader context that influences their clients' choices, decisions, and safer sex practices. Most providers also lacked the skills to help clients better communicate with their partners.

In all three programs staff had a good set of basic skills. They listened carefully, were empathetic, dedicated, and willing to learn. To help them learn to talk to clients about sexuality and gain a more holistic approach to sexual health, project leaders observed how educators and counselors implemented their new skills and knowledge, provided immediate feedback, and identified additional training needs as the project progressed.

A key factor in preparing staff for this process was sexuality training, which centered on helping providers clarify their own values and biases toward sexuality and sexual behaviors. The goal was to enable staff to be more objective when helping clients understand their circumstances and consider their options. In some cases, this represented a fundamental change in how staff approached their work. As Victoria Jennings of Georgetown University's Natural Family Planning Project remarked, "Promoters and providers were being asked to become facilitators and educators." Participatory exercises were used to $\mathrm{ex}^{-}$ plore several themes: becoming comfortable with sexual language, clarifying values, exploring individual staff's own sexuality and sexual development, examining gender roles and power imbalances, brainstorming about other ways of practicing safer sex, discussing strategies to promote sexual communication and negotiation, and clarifying the effect of certain family planning methods on sexual relations. ${ }^{1}$ Processes such as these may also encourage staff to change their own behavior. As one participant wondered, "Why should we expect our clients to behave more responsibly than the staff, program managers, and policymakers do?"

Not surprisingly, a primary barrier to engaging clients in a more open dialogue about their contraceptive needs is the fact that many staff have their own basic questions with regard to sexuality. When staff in Honduras had the chance to pose questions anonymously, they asked: Can you practice anal sex with a female partner? Why did I bleed a lot during my first sexual encounter? Is masturbation bad? Is oral sex satisfying? Are there people who are stimulated sexually by their spouse but do not have orgasm? Why? Why do some women have fear at the moment of penetration? Training that allows staff to reflect on their own feelings and experiences can create a self-awareness and empathy that influences the client-provider interaction in a positive way.

Helping providers to become more comfortable with promoting condom use requires overcoming professional and personal biases against the method. Several months after the training in Honduras and Brazil, staff reported an increase in their own condom use. A female provider in Honduras now swears by condoms and tells clients of her own positive experience in using them. In Jamaica, staff who previously regarded condoms as a less effective family planning method found that when used correctly, condoms have a potentially high efficacy rate. Staff now teach the proper use of condoms. They also recommend the simultaneous use of a hormonal method or IUD for pregnancy prevention and condoms for STD prevention. 
Developing acceptance of these new ideas and approaches provides an opportunity to involve a wide range of staff-counselors/educators, nurses, physicians, administrative staff, drivers, and cleaners - thus providing most people with a greater sense of mission and importance. In Jamaica, receptionists and the driver now conduct informal waiting-room discussions. In Honduras, when she is not busy with Pap smears, the cytologist starts informal discussions with waiting clients. As Margarita Diaz pointed out, this approach also ensures that "the various messages within a clinic add up."

Shifting from simply giving family planning information to engaging clients in a two-way exploration of their sexual lives has not always been a smooth process, Julie Becker said. For example, giving people new areas of responsibility can challenge traditional structures and lines of authority. Peer influence and a healthy element of competition have also emerged. Each regional center now tries to surpass innovations introduced by other centers. One promising strategy developed in Brazil is the implementation of small-group interventions in which women have a place to express their concerns, support each other, and practice their communication skills. One woman, after participating in several group discussions, related her success: "After fighting many times, I got my husband to use a condom. I told him that his penis was thicker and more pleasurable [with a condom] and I screamed and wailed. He has been using condoms now for three months. Now I feel more secure and indeed feel pleasure." Becker said such examples suggest that some clients may not be ready to involve their partners directly and that they would benefit from speaking first with other clients of their own sex.

Commenting on the IPPF/WHR project, Elaine Murphy of PATH noted the need to test these interventions and to use the data to establish the benefits for clients and staff. Such evidence could help reinforce program managers' perceptions that they are having a positive effect both on meeting clients' needs and on utilization of services. It will also be crucial to procure the necessary funding, space, and political support from donors and senior policymakers to encourage further experimentation. As Murphy concluded, "Too often the refrain is, 'We can't afford to do this.' Perhaps we should demonstrate that 'We can't afford not to do this."

\footnotetext{
${ }^{1} A$ detailed description of the training session, and of the changes undertaken by the providers in each program, will be available in a forthcoming edition of the Quality/Calidad/Qualité booklet series.
} 

more effective contraceptive use suggest that addressing sexuality is worth the investment.

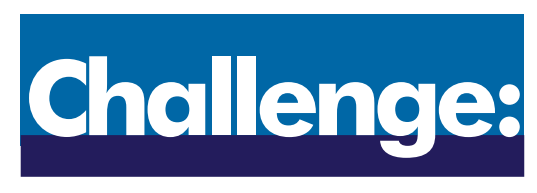

\author{
To assist family planning \\ programs in developing an \\ appropriate range of \\ reproductive and sexual \\ health services.
}

$\mathbf{M}$ anagers of family planning programs need guidance as to the many aspects of services that could be enhanced by addressing issues of sexuality. Unfortunately, although the words "gender," "sexuality," and "sexual health" appear with increasing frequency in policy and project documents, they are rarely accompanied by a discussion of their meaning or their relation to family planning services. Family planning staff and researchers receive little explanation of how these issues pertain to their work, and consequently perceive them as an added demand on service delivery systems.

In fact, time is a precious commodity in many family planning clinics, particularly those in Latin America where financial sustainability is a major concern. Staff in the three IPPF/WHR affiliates discussed in the previous section were initially concerned that their new responsibilities would require spending a long time with each client. However, they found that, in many cases, they can quickly elucidate important information that helps their clients make and implement decisions on their own behalf by using a different starting pointasking questions about the client's sexual life rather than starting with a description of methods.

One counselor in Honduras spoke with a client for several minutes before discovering that, although the client had come in requesting an IUD, she was worried about contracting an STD from her husband, who traveled frequently. The client was reluctant to ask her husband to use condoms because it might imply a lack of trust. Nor, as the mother of eight children, could she abide the idea of becoming pregnant again. Together, she and her counselor decided that she could tell a white lie to her husband. She had an IUD inserted as a backup measure, but told her husband that the clinic denied her request and that he would have to use condoms. Although this strategy may not meet the longerterm goal of helping clients communicate with their partners and engage in joint reproductive decisionmaking, it respected the client's privacy and met more than one of her immediate needs. 
In another example, Robert Miller of the Population Council presented data that challenged the common assumption that service delivery points (SDPs) are typically overburdened. A total of fourteen Situation Analysis studies (quick appraisals of services offered to and received by clients) in Africa reveal that one-quarter of SDPs serve approximately 75 to 80 percent of family planning clients. Furthermore, the studies revealed significant amounts of unused capacity in the three-quarters of the SDPs that serve relatively few clients, leaving much room for providing additional services.

Opportunities also exist for service providers to initiate direct contact with men and to talk to female clients about often-neglected male methods. Data from two successive Situation Analysis studies in Kenya (1988 and 1995) reveal that this may already be happening. Between these two dates, the proportion of new clients who were informed about condoms increased from 60 percent to 71 percent; the proportion informed about vasectomies rose from 3 percent to 14 percent.

Jewel Quallo-Rosberg, executive director of the Belize Family Life Association (BFLA), acknowledged that there is room for improvement in the way family planning services respond to clients' health needs. Quallo-Rosberg described how the association has shifted its focus from family planning to sexual and reproductive health at both an institutional and service-delivery level. In the clinic, a range of new services were added, including a lab to back up STD screening and Pap smears, AIDS prevention counseling, referrals for specialized treatment, and pre- and post-natal services for disadvantaged teenage mothers. BFLA is also undertaking an ambitious experiment to train community leaders as reproductive health facilitators and is establishing a special center to serve low-income teens.

Adding community education to BFLA's work was extremely challenging for staff, who had to shift from "teaching" clients to facilitating an exchange of information. The two new field workers coordinating this component needed training, as did the nurses in the target areas. Training workshops helped the community educators realize that the knowledge that they had about sexuality was a valid basis for their work, and they soon gained confidence in their ability to handle their required tasks. The staff now fulfill three simultaneous roles: providing services and information; raising awareness about the causes of poor health and poor human interaction; and facilitating and supporting clients' own analysis, planning, and action. As BFLA staff moved from the clinic into the community, they have had to learn new ways of maneuvering, seeing, and relating.

Participants in the workshops included community health workers, traditional birth attendants, and representatives from breast-feeding and other local health groups. The goals of the association's community outreach effort include: (1) providing services that are more relevant to people's sexual lives; (2) promoting community action to improve gender interaction; and (3) improving clients' use of referral services for other needs. Participants in rural areas appear to be more receptive than the urban poor to these efforts, though both groups participated eagerly in the initial workshops. Role playing exercises have generated laughter and learning, and participants have taken advantage of the opportunity to write poems that reflected their thoughts, feelings, and concerns about sex (see page 25). Men and women have had the opportunity to engage in an open 
discussion, to discover their biases, and to consider the other sex's point of view. In the early workshops, some men reacted to women's responses by walking out. This led BFLA to train discussion leaders in facilitation skills to maintain the open flow of conversation.

While BFLA already had considerable experience working with teens, in schools and through an "Under-20 Club," opening a teen center in a poor, urban neighborhood posed a new challenge. There, BFLA staff encountered a cohort of low-income youths, some of them gang members, who were much less educated and much more sexually active than their usual teen clientele. The association is testing new outreach strategies, including the formation of a project called Belizean Youth with an Aim for Prosperity (BYAP), which trains youth in dramatic techniques as a way to help them communicate more effectively with their peers.

The new teen program has helped BFLA improve its public image. Once seen as interested only in reducing population growth, the association is now viewed as promoting the welfare of young people. Its new programs have generated both press coverage and a willingness among government officials, church leaders, and others to collaborate on common concerns.

Changes at the clinical level have enabled the association to respond to a broader range of clients' needs. New services include Pap smears and STD diagnosis and treatment, as well as referrals for specialized treatment. The greatest challenge in clinical practice was the counseling process. As with the three IPPF affiliates whose work is described above, a more client-centered approach required staff to move beyond the traditional outlining of methods and side effects to a more interactive and sensitive approach to counseling clients. New counseling protocols were developed and staff were retrained. Originally, the project design included a full-scale pre-natal service for teens with regular clinical exams, blood work, and the like, in addition to information services. In order to keep things manageable, however, the association limited itself to providing the educational component.

As more family planning clinics begin to incorporate sexual and reproductive health into their programs, they would do well to heed the lessons already learned and the challenges already identified. Successfully managing this programmatic shift takes time (more than just one training session), flexibility, communication with community members, new ways to gather and evaluate qualitative data, and the patience to make changes slowly but surely. 


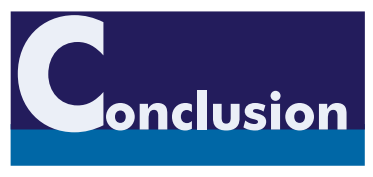

exuality touches on some of the most fundamental aspects of human life. Therefore, it should come as no surprise that people all over the world value opportunities to ask questions and to talk honestly and openly about their sexual lives and relationships. All too often, however, sexuality as a topic of discussion is relegated to the private sphere as something too personal to discuss even with a partner or family member. The root of this inability to speak frankly about sex may not be embarrassment. Rather, it suggests a reluctance to talk about the inequalities, and sometimes abuses, of power that exist among intimate partners. These inequalities are dependent upon a number of characteristics-age, race, class, and, most often, gender-and have significant implications for the delivery of contraceptive and reproductive health services.

Too often women-and sometimes men-lack the power to make and implement decisions about contraceptive use and disease prevention. In order to respond effectively to this situation, researchers and program managers must develop a better understanding of the social context of clients' sexual and reproductive lives. In addition to eliciting more information about clients' reproductive goals, providers need information about the level of cooperation or coercion in a relationship, the possibility of other sexual partners in any primary relationship, and what role sex plays in the relationship. Do clients and their partners agree on the goal of limiting fertility, what method to use, and who will be responsible for its effective use? Or is one partner acting independently or surreptitiously to prevent an unwanted pregnancy? Do they also need to think about preventing disease? Are clients comfortable with their understanding of reproductive physiology, or would they like more information? These questions can help family planning program managers assess and meet clients' needs and determine which outcomes to measure.

Further, if family planning programs expand their objectives from reducing the total number of births to improving healthy decisionmaking among their clients, they must forge alliances with other actors in their communities. Power, and inequalities of power, are at the root of many unhealthy and unwanted reproductive outcomes. To successfully alter these relationships, family planning and AIDS-prevention programs will need to combine forces with agencies and organizations that directly address social relationships. For example, they need to capitalize on programs that are working to improve girls' and women's access to education, credit, or job training, which are known to strengthen women's bargaining positions within intimate relationships and within families. They 
need to work with advocacy agencies and researchers trying to define and promote women's human rights. They need to reach out to agencies working on issues of child development and to promote greater paternal involvement in raising children.

A vital but often neglected partner in this process is the media. Popular media tools such as video, music, and comics can be used to promote alternative models of partnership relations, sexual behavior, and negotiation. As the Belize Family Life Association learned, changes in service delivery-particularly those that are seen to be responsive to community interests-can become media stories in and of themselves. In addition to creating greater visibility for a particular program, this kind of attention can help raise awareness and initiate public discussion about issues that are difficult to change on a one-to-one basis.

In the post-Cairo era, family planning program managers are likely to find themselves operating in an environment that demands increased accountability - to both clients and donors-on a range of reproductive health issues that includes HIV/AIDS and reproductive rights. To be successful in this environment, family planning programs need to design and evaluate services based on whether or not they meet clients' reproductive health needs, not in terms of how many contraceptives they have delivered or how many clients they have served. This new basis requires shifting from a medical model, which defines a successful transaction as giving a client the most effective contraceptive technology, to a contextual approach in which providers and program managers see their roles as helping to facilitate informed reproductive decisionmaking on the part of their clients. The difficulties of making this transition should not be underestimated, nor should the potential benefits. Sexuality is central to family planning programs and reproductive health programs, particularly those addressing STD/ HIV prevention. Further, as illustrated by the presentations in this report, sexuality is a subject of importance to both clients and providers. By dealing more openly with issues such as pleasure and power, family planning and reproductive health programs will better serve their current clients and attract many new ones. 


\section{Parricipants}

José Aguilar

Fundación Mexicana para la

Planeación Familiar (MEXFAM)

Calle Juarez 208

Tlalpan 14000 DF Mexico

525/573-7268

Julie Becker

IPPF/WHR

120 Wall Street

New York, NY 10005

212/248-6400

Ann Blanc

DHS/Macro International Inc.

11785 Beltsville Drive, 3rd Floor

Calverton, MD 20705

301/572-0946

Debra Boyer

University of Washington

Center for Health Training

400 Tower Building

1809 7th Avenue

Seattle, WA 98101-1316

206/447-9538

Martha Brady

Population Council

One Dag Hammarskjold Plaza

New York, NY 10017

212/339-0500

George Brown

Population Council

One Dag Hammarskjold Plaza

New York, NY 10017

212/339-0500

Judith Bruce

Population Council

One Dag Hammarskjold Plaza

New York, NY 10017

212/339-0500

Stuart Burden

MacArthur Foundation

140 Dearborn Street

Suite 1100

Chicago, IL 60603

312/726-8000

Michèle Burger

Independent Consultant

11 Riverside Drive

8WE

New York, NY 10023
Lucella Campbell

IPPF/WHR

120 Wall Street

New York, NY 10005

212/248-6400

Christa Coggins

Population Council

One Dag Hammarskjold Plaza

New York, NY 10017

212/339-0500

Berengere DeNegri

Academy for Educational Develop-

ment

1255 23rd Street, NW

Suite 400

Washington, DC 20037

202/884-8700

Juan Diaz

Population Council

Caixa Postal 6181

13081-970 Campinas

Sao Paulo, Brazil

55-192-392-856

Margarita Diaz

CEMICAMP

Caixa Postal 6181

CEP 13.081-970

Campinas, Sao Paulo, Brazil

55-192-392-856

Bruce Dick

UNICEF

3 UN Plaza

New York, NY 10017

212/303-7944

Diane di Mauro

Sexuality Research

Assessment Project

Social Science Research Council

810 7th Avenue

New York, NY 10019

212/377-2700

Betty Farrell

Pathfinder International

9 Galen Street

Suite 217

Watertown, MA 02172

617/924-7200 
Elizabeth Ferreras

Asociacion Dominicana

Pro-Bienestar de la Familia (PRO-

FAMILIA)

Socorro Sanchez \# 160, Zona 1

Apartado 1053

Santo Domingo

República Dominicana

(809) 688-3566 / 689-0141

Laurie Fox

Family Health International

P.O. Box 13950

Research Triangle Park, NC 27709

919/544-7040

Judith F. Helzner

IPPF/WHR

120 Wall Street

New York, NY 10005

212/248-6400

Margaret Hempel

The Ford Foundation

320 East 43rd Street

New York, NY 10017

212/573-5000

Hilary Hughes

IPPF

Regent's College

Regent's Park

London NW14NS

United Kingdom

44-171-486-0741

Jane Hughes

The Rockefeller Foundation

420 Fifth Avenue

New York, NY 10018-2702

212/869-8500

Suzanne Hurley

Centers for Disease Control and Preven-

tion

Reproductive Health Unit

3005 Chamblee Tucker Road

Atlanta, GA 30341

770/488-5612

Andrea Irvin

International Women's

Health Coalition

24 East 21 st Street

New York, NY 10010

212/979-8500

Jodi Jacobson

Health and Development

Policy Project

6930 Carroll Avenue

Suite 430

Tacoma Park, MD 20912

301/270-1182

Victoria Jennings

Georgetown University

Natural Family Planning Project

School of Medicine

Dept. of OB/GYN

3800 Reservoir Road
Washington, DC 20007

202/625-3686

Ann Jimerson

Academy for Educational Development

1255 23rd Street, NW

Suite 400

Washington DC 20037

202/884-8700

Ann Leonard

Population Council

One Dag Hammarskjold Plaza

New York, NY 10017

212/339-0500

Ronnie Lovitch

Independent Consultant

509 2nd Street

\#4R

Brooklyn, NY 11215

718/786-2655

Mia MacDonald

International Women's

Health Coalition

24 East 21 st Street

New York, NY 10010

212/979-8500

Elizabeth McGrory

Population Council

One Dag Hammarskjold Plaza

New York, NY 10017

212/339-0500

Erin McNeill

USAID

1601 North Kent Street

Roslyn, VA 22209

703/875-4793

Barbara Mensch

Population Council

One Dag Hammarskjold Plaza

New York, NY 10017

212/339-0500

Robert Miller

Population Council

One Dag Hammarskjold Plaza

New York, NY 10017

212/339-0500

Kirsten Moore

27 West Broad Street

Hopewell, NJ 08525

609/466-8788

Elaine Murphy

Program for Appropriate

Technology in Health

1990 M Street, NW

Washington, DC 20036

202/822-0033

Sia Nowrojee

Independent Consultant

505 North Roosevelt Boulevard

B221

Falls Church, VA 22044

703/533-6978 